\title{
Sustainable supercapacitor electrodes produced by the activation of biomass with sodium thiosulfate
}

\author{
Marta Sevilla*, Noel Diez, Guillermo A. Ferrero and Antonio B. \\ Fuertes*
}

Instituto Nacional del Carbón (CSIC), Fco. Pintado Fe 26, Oviedo 33011, Spain

*Corresponding authors: martasev@incar.csic.es and abefu@incar.csic.es

\begin{abstract}
High-surface area carbons are produced from biomass-based products (wood sawdust and tannic acid) by means of an environmentally friendly process based on the use of sodium thiosulfate as activating agent and an inert salt $(\mathrm{KCl})$ that serves as a confinement medium for the activation reaction. These porous carbons have high BET surface areas of up to $2650 \mathrm{~m}^{2} \mathrm{~g}^{-1}$, large pore volumes of up to $2.3 \mathrm{~cm}^{3} \mathrm{~g}^{-1}$ and a porosity that combines micro- and mesopores in different amounts depending on the quantity of activating agent employed. Such carbons have two additional remarkable properties: a) they are S-doped (2 - $6 w t \%$ S) and b) they have good electrical conductivities in the 2.5 $-4.5 \mathrm{~S} \mathrm{~cm}^{-1}$ range. The above properties make these carbon materials highly attractive as supercapacitor electrodes. Indeed, when tested in a variety of electrolytes $\left(\mathrm{H}_{2} \mathrm{SO}_{4}, \mathrm{TEABF}_{4} / \mathrm{AN}\right.$ and EMImTFSI) using commercial-level mass loadings, they show high specific capacitances (up to $200 \mathrm{~F} \mathrm{~g}^{-1}, 140 \mathrm{~F} \mathrm{~g}^{-1}$ and $160 \mathrm{~F} \mathrm{~g}^{-1}$ in aqueous, organic and ionic liquid electrolytes, respectively) and high capacitance retention at high rates in all the electrolytes in combination with a good stability under cycling and floating modes.
\end{abstract}

\section{Keywords}

Green synthesis, Porous carbon, Biomass, Sodium thiosulfate, S-doped carbon, Supercapacitors 


\section{Introduction}

Porous carbons are a key component in many energy storage systems, such as supercapacitors and lithium batteries. Taking into account their irreplaceable role and the predicted steady growth of the production of these types of devices, a great demand for porous carbons can be expected in the next few years. Hence, the production of carbon materials for such applications needs to be optimized. The procedures used to produce porous carbons need to be based on two main criteria: a) the carbon precursors must be abundantly available, cost-effective and renewable materials (i.e. biomass or biomassbased products), and b) the process must be scalable and environmentally friendly, which excludes the use of corrosive and harmful substances [1].

For using porous carbons in energy storage systems, the optimization of their structural characteristics, which must be adapted for each specific application, is important. For their use as electrodes in supercapacitors, these materials need to possess a high specific surface area together with an appropriate pore size distribution that combines narrow micropores suitable for the accommodation of ions with larger pores (supermicropores and mesopores) that favor ion transport and serve for storing electrolyte [2]. In order to produce porous carbons with these specific characteristics, various refined synthesis strategies have been developed: templating methods [3-5] or selective etching of metals from metal carbides [6]. However, in spite of the advances mentioned above, chemical activation with $\mathrm{KOH}$ continues to be the preferred method to produce highly porous carbon materials with a large surface area $\left(>2000 \mathrm{~m}^{2} \mathrm{~g}^{-}\right.$

$\left.{ }^{1}\right)$ and a porosity that combines micropores and small mesopores [7, 8]. Unfortunately, due to its high corrosiveness and toxicity, the use of $\mathrm{KOH}$ and 
other popular chemical activating substances, such as phosphoric acid, sodium hydroxide or zinc chloride, entails serious economic and environmental problems that hinder scaling-up. There is, therefore, an urgent need to develop new procedures for the production of porous carbons by means of greener synthesis strategies based on harmless activating chemical agents and sustainable, cost-effective carbon precursors such as biomass-based products and sub-products.

We and other authors have investigated the use, as activating agents, of several less-corrosive potassium compounds such as potassium carbonate [9, 10], potassium bicarbonate $[11,12]$ or potassium oxalate $[13,14]$ to produce highly porous carbons, which exhibit a high performance as electrodes in supercapacitors. Likewise, we recently reported a novel environmentally friendly synthesis strategy for producing highly porous carbons from a variety of biomass-based products (i.e. gelatin, sucrose, glucose) [15]. This procedure is based on harmless ingredients such as sodium thiosulfate as activating agent and an inert salt $(\mathrm{KCl})$ that provides a suitable reaction medium. The synthesis scheme involves three simple steps: a) mixing the reactants (i.e. a biomassbased substance, potassium chloride and sodium thiosulfate) by grinding them, b) heat-treating them at temperatures in the $800-900{ }^{\circ} \mathrm{C}$ range and c) collecting the resultant carbon material from the carbonized solid by harmless washing with water. This activation procedure provides a green and sustainable strategy for producing porous carbons since only affordable and environmentally friendly ingredients (i.e. biomass, $\mathrm{KCl}, \mathrm{Na}_{2} \mathrm{~S}_{2} \mathrm{O}_{3}$ and water) are involved. Moreover, the by-products generated during the washing step with water can be easily reoxidized by a simple $\mathrm{O}_{2}$ bubbling $[16,17]$, giving rise to a saline solution 
containing the ingredients used for the synthesis of the carbon (sodium thiosulfate and $\mathrm{KCl}$ ), which could then be recirculated to the activation system. In this work, we investigate the implementation of porous carbons synthesized in the way just described as electrodes in supercapacitors. Moreover, we have extended this synthesis strategy from simple biomass-derived molecules to more complex compounds (tannic acid) and also a biomass residue (eucalyptus sawdust), to demonstrate the general applicability of this methodology. The porous carbons thus obtained have high BET surface areas of up to $2600 \mathrm{~m}^{2} \mathrm{~g}^{-1}$ and large pore volumes of up to $2.3 \mathrm{~cm}^{3} \mathrm{~g}^{-1}$. Interestingly, this type of carbon material is S-doped as a certain amount of sulfur is incorporated into the carbon framework during the activation process. The applicability of porous carbons produced by activating different biomass-based products (i.e., eucalyptus sawdust, tannic acid and gelatin) with $\mathrm{Na}_{2} \mathrm{~S}_{2} \mathrm{O}_{3}$ as electrodes in supercapacitors is analyzed in three different types of electrolyte (i.e. $\mathrm{H}_{2} \mathrm{SO}_{4}$, TEABF 4 /AN and EMImTFSI). The results confirm the versatility of this synthesis methodology for producing porous carbons with properties adapted for the targeted electrolyte. What is more, the performance of the developed materials compares favourably with state-of-the-art porous carbons.

\section{Experimental}

\subsection{Preparation of porous carbons}

In a typical synthesis procedure, $3 \mathrm{~g}$ of carbon precursor (e.g., eucalyptus sawdust from a local sawmill or tannic acid and gelatin purchased from Aldrich) were mixed by hand-grinding them in a mortar with $10 \mathrm{~g}$ of potassium chloride (Aldrich) and between $2 \mathrm{~g}$ and $4.5 \mathrm{~g}$ of sodium thiosulfate (Alfa-Aesar). The resulting powder was heated under $\mathrm{N}_{2}$ up to $800{ }^{\circ} \mathrm{C}$ at a 
heating rate of $5{ }^{\circ} \mathrm{C} \min ^{-1}$, and held at this temperature for $1 \mathrm{~h}$. Finally, the carbonized solid was washed with distilled water for several hours and the carbon particles were collected by filtration and dried at $120^{\circ} \mathrm{C}$. The carbon samples were denoted as ESK-X, TAK-X or GEK-X for sawdust, tannic acid and gelatin respectively, where $X$ is the $\mathrm{Na}_{2} \mathrm{~S}_{2} \mathrm{O}_{3}$ /carbon precursor weight ratio (i.e., $0.7,1,1.3$ or 1.5$)$. In the case of tannic acid, a carbon sample was also prepared by lyophilization of a solution of the reaction ingredients instead of by milling, material labelled as TAK-1.5L. Carbon samples were also prepared from eucalyptus sawdust and tannic acid without using $\mathrm{KCl}$ and were labelled as $E S-X$ and $T A-X$.

\subsection{Physicochemical Characterization}

Scanning electron microscopy (SEM) images were recorded on a Quanta FEG650 (FEI) instrument, whereas transmission electron microscopy (TEM) images were obtained on a JEOL (JEM 2100-F) apparatus operating at $200 \mathrm{kV}$. The $\mathrm{N}_{2}$ sorption isotherms of the carbon samples were measured at $-196^{\circ} \mathrm{C}$ using a Micromeritics ASAP 2020 sorptometer. The apparent surface area was calculated by the BET method. An appropriate relative pressure range was selected to ensure a positive line intersect of multipoint BET fitting $(C>0)$ and an increase of $\mathrm{V}_{\mathrm{ads}}\left(1-\mathrm{p} / \mathrm{p}_{\mathrm{o}}\right)$ with $\mathrm{p} / \mathrm{p}_{\mathrm{o}}$ [18]. The total pore volume was determined from the amount of nitrogen adsorbed at a relative pressure $\left(p / p_{o}\right)$ of 0.99 . The pore size distributions (PSD) were determined by means of the Quench Solid State Density Functional Theory (QSDFT) method for nitrogen. Xray diffraction (XRD) patterns were obtained on a Siemens D5000 instrument operating at $40 \mathrm{kV}$ and $20 \mathrm{~mA}$, using a $\mathrm{Cu}-\mathrm{K} \alpha$ radiation source. X-ray photoelectron spectroscopy (XPS) was carried out on a Specs spectrometer, 
using Mg KR (1253.6 eV) radiation from a double anode at $150 \mathrm{~W}$. Calibration of the binding energies for the high resolution spectra was performed by setting the $\mathrm{C}$ 1s signal to $284.5 \mathrm{eV}$. The S2p spectrum was deconvoluted on the basis of a separation between peaks in each of the doublets of $\sim 1.2 \mathrm{eV}$ and taking into account that the ratio of areas between the spin-up state, $\mathrm{j}_{3 / 2}$, and the spindown state, $j_{1 / 2}$, is equal to 2 . The elemental analysis of the samples was carried out on a LECO CHN-932 microanalyzer. The electrical conductivity and the packing density of the carbon powders were determined in a homemade apparatus by pressing the powders between two plungers into a hollow nylon cylinder (inner diameter of $8 \mathrm{~mm}$ ), and applying a pressure of $7.1 \mathrm{MPa}$.

\subsection{Electrochemical characterization}

The electrochemical measurements were carried out in two-electrode Swagelok ${ }^{\mathrm{TM}}$ type cells in $1 \mathrm{M} \mathrm{H}_{2} \mathrm{SO}_{4}, 1 \mathrm{M} \mathrm{TEABF}_{4} / \mathrm{AN}$ ( $\mathrm{AN}=$ acetonitrile) and neat EMImTFSI (1-Ethyl-3-methylimidazolium bis(trifluoromethylsulfonyl)imide) (99 \%, Ionic Liquids Technology, Germany) electrolyte solutions. In addition, Swagelok ${ }^{\mathrm{TM}} \mathrm{T}$-type cells were used to carry out synchronous two- and threeelectrode measurements in ionic liquid electrolyte employing silver as pseudoreference electrode, so that the potential of each electrode can be monitored. The supercapacitors were assembled using two carbon electrodes of comparable mass and thickness (a carbon loading of $9-11 \mathrm{mg} \mathrm{cm}^{-2}$, a thickness $\sim 240-470 \mu \mathrm{m}$ depending on the material), electrically isolated by several glassy fibrous separators. The electrodes were prepared from a slurry consisting of 85 wt.\% of active material, 10 wt.\% of polytetrafluoroethylene (PTFE) binder (Aldrich, 60 wt.\% suspension in water) and 5 wt.\% of Super C65 (Timcal). The supercapacitors with aqueous electrolytes were assembled under an air 
atmosphere using gold current collectors, whereas those with organic and ionic liquid electrolytes were assembled in an argon-filled glovebox using stainless steel current collectors. The electrochemical characterization was performed at room temperature using a computer-controlled potentiostat (Biologic VMP3 multichannel generator) and consisted of cyclic voltammetry experiments, electrochemical impedance spectroscopy studies and galvanostatic charge/discharge cycling tests.

Electrochemical impedance spectroscopy (EIS) measurements were performed at open circuit voltage (i.e. $0 \mathrm{~V}$ ) in the as-assembled supercapacitors within the frequency range of $1 \mathrm{mHz}$ to $100 \mathrm{kHz}$ and a $10 \mathrm{mV} \mathrm{AC}$ amplitude. Nyquist and Bode plots were recorded to characterize the impedance of the tested samples. The specific gravimetric capacitance of the cell, $C_{\text {EIS }}\left(F g^{-1}\right)$, was calculated according to the following formula and normalized with respect to specific gravimetric capacitance at $1 \mathrm{mHz}$ :

$$
\mathrm{C}_{\text {cell,EIS }}=\frac{|\operatorname{Im}(\mathrm{Z})|}{2 \pi \mathrm{f} \cdot\left[(\operatorname{Im}(\mathrm{Z}))^{2}+(\operatorname{Re}(\mathrm{Z}))^{2}\right] \cdot \mathrm{m}}
$$

where $f$ is the operating frequency $(\mathrm{Hz}), \operatorname{Im}(Z)$ and $\operatorname{Re}(Z)$ are the imaginary and real components of the total resistance of the device $(\mathrm{Ohm})$, and $\mathrm{m}$ is the mass of carbon material in the supercapacitor (grams).

Cyclic voltammetry (CV) experiments were conducted using a cell voltage of $1 \mathrm{~V}$ in $1 \mathrm{M} \mathrm{H}_{2} \mathrm{SO}_{4}, 2.7 \mathrm{~V}$ in $1 \mathrm{M} \mathrm{TEABF}_{4} / \mathrm{AN}$, and $3 \mathrm{~V}$ in EMIMTFSI, at increasing sweep rates from $5 \mathrm{mV} \mathrm{s}^{-1}$ to $500 \mathrm{mV} \mathrm{s}^{-1}$. Plots of cell gravimetric capacitance vs. voltage were calculated using the formula:

$$
\mathrm{C}_{\text {cell }}=\frac{\mathrm{I}}{\vartheta \cdot \mathrm{m}}
$$

where $\mathrm{I}=$ current $(\mathrm{A})$ and $\mathrm{v}=$ scan rate $\left(\mathrm{V} \mathrm{s}^{-1}\right)$. 
Galvanostatic charge/discharge cycling (GCD) was carried out using the same cell voltages as in CV experiments and at increasing current densities from 0.2 to $100 \mathrm{~A} \mathrm{~g}^{-1}$ (based on the active mass of one electrode). The specific gravimetric capacitance of a single electrode was determined from the galvanostatic cycles by means of the formula:

$$
\mathrm{C}_{\text {electrode }}=\frac{4 \mathrm{I}}{\left(\frac{\mathrm{dV}}{\mathrm{dt}}\right) \cdot \mathrm{m}}
$$

where $\mathrm{dV} / \mathrm{dt}$ is the slope of the discharge curve $\left(\mathrm{V} \mathrm{s}^{-1}\right)$. As most supercapacitors are operated in the range of $V_{\max }$ to approximately $1 / 2 V_{\max }$, the upper half of the discharge curve was used to determine the slope of the discharge curve [19].

To trace the Ragone plots, the specific energy $\left(\mathrm{Wh} \mathrm{kg}^{-1}\right)$ and power (kW $\mathrm{kg}^{-1}$ ) were calculated using the following formulae:

$$
\begin{aligned}
& \mathrm{E}=\frac{1}{2} \mathrm{C}_{\text {cell }} \Delta \mathrm{V}_{\mathrm{d}}^{2} \\
& \mathrm{P}=\frac{\mathrm{E}}{\Delta \mathrm{t}_{\mathrm{d}}}
\end{aligned}
$$

where $\Delta V_{d}$ is the operation voltage $\left(V_{\max }-I R_{d r o p}\right), C_{c e l l}$ is the cell capacitance determined through GCD and $\Delta \mathrm{t}_{d}$ is the discharge time.

To calculate the volumetric performance of the materials, the packing density of the electrode was used. This density was determined from its thickness (measured with a micrometer caliper) and its area $\left(0.785 \mathrm{~cm}^{2}\right)[20]$.

Long-term cycling stability was evaluated by continuous galvanostatic charge/discharge cycling over $5000-10000$ cycles at 3 or $5 \mathrm{~A} \mathrm{~g}^{-1}$ and at the maximum cell voltage, i.e. $1 \mathrm{~V}$ in $\mathrm{H}_{2} \mathrm{SO}_{4}, 2.7 \mathrm{~V}$ in $1 \mathrm{M} \mathrm{TEABF}_{4} / \mathrm{AN}$ and $3 \mathrm{~V}$ in EMImTFSI. Floating tests (i.e., potentiostatic hold) were also performed at maximum cell voltage for $24-48 \mathrm{~h}$. 


\section{Results and discussion}

\subsection{Structural, textural and chemical properties of the porous carbons}

A schematic illustration of the synthesis procedure is shown in Scheme 1. The activation process is essentially based on the high-temperature redox reaction between the carbonaceous matter and the sodium sulfate generated by the decomposition of sodium thiosulfate $\left(4 \mathrm{Na}_{2} \mathrm{~S}_{2} \mathrm{O}_{3} \rightarrow 3 \mathrm{Na}_{2} \mathrm{SO}_{4}+\mathrm{Na}_{2} \mathrm{~S}_{5}\right.$ at $>250$ $\stackrel{\circ}{ } \mathrm{C})$ :

$\mathrm{Na}_{2} \mathrm{SO}_{4}+x \mathrm{C} \rightarrow \mathrm{Na}_{2} \mathrm{~S}+y \mathrm{CO} / \mathrm{CO}_{2}$

A detailed analysis of the reaction mechanism is given in our previous report [15]. It is interesting to note that, in spite of the fact that $\mathrm{Na}_{2} \mathrm{SO}_{4}$ is the actual activating agent, when $\mathrm{Na}_{2} \mathrm{SO}_{4}$ is used instead of $\mathrm{Na}_{2} \mathrm{~S}_{2} \mathrm{O}_{3}$, materials with lower pore development are obtained, as shown in our recent work [15].

The macroscopic structure of the porous carbons was examined by means of scanning electron microscopy (SEM). The morphology of the carbon particles depends on the melting properties of the raw materials. Thus, in the case of a non-melting precursor such as sawdust, the porous carbon particles retain the typical structure of wood, as illustrated by the SEM images shown in Figures $1 \mathrm{a}$ and $1 \mathrm{~b}$. By contrast, when the precursors melt during the heat treatment (i.e., tannic acid melts at around $220 \stackrel{\circ}{ } \mathrm{C}$ and gelatin at $<100 \stackrel{\circ}{\circ}$ ), the inert solid particles present in the mixture (i.e. $\mathrm{KCl}$ and $\mathrm{Na}_{2} \mathrm{SO}_{4}$ ) act as templates that direct the formation of a foam-like structure. This morphology is retained by the porous carbon (Figures $1 \mathrm{c}$ and $1 \mathrm{~d}$ ). In relation to the activation process at $800{ }^{\circ} \mathrm{C}$, it is important to point out that the carbonaceous particles are immersed within a liquid phase constituted by $\mathrm{KCl}$ (melting point of $\sim 770$ 
${ }^{\circ} \mathrm{C}$ ) and the $\mathrm{Na}_{2} \mathrm{SO}_{4}-\mathrm{Na}_{2} \mathrm{~S}$ system that forms a liquid phase at temperatures > $740 \stackrel{\circ}{\mathrm{C}}[21]$. Under these conditions, the melted $\mathrm{KCl}$ will act as a confinement medium which, in this way, will reinforce the contact between the solid carbonaceous matter and the $\mathrm{Na}_{2} \mathrm{SO}_{4}-\mathrm{Na}_{2} \mathrm{~S}$ liquid system, enhancing the reactivity [15]. This hypothesis is supported by the fact that the final carbonized product appears as a hard monolithic structure (see Figure S1).

The porous characteristics of the carbon samples were investigated by $\mathrm{N}_{2}$ physisorption. The main textural characteristics (i.e., BET surface area, pore volume and micropore volume) of the porous carbons derived from sawdust and tannic acid are listed in Table 1, while Figure 2 shows the nitrogen sorption isotherms and the pore size distributions. Table S1 and Figure S2 provide the textural properties of the gelatin-based carbons. An analysis of these results evidences that the use of inert $\mathrm{KCl}$ particles is essential to obtain carbon materials with good textural properties. For example, in the case of sawdust, whereas in the absence of $\mathrm{KCl}$, the carbon sample (ES-1.5) shows a moderate textural development $\left(S_{B E T}=1070 \mathrm{~m}^{2} \mathrm{~g}^{-1}\right.$ and $\left.V_{p}=0.56 \mathrm{~cm}^{3} \mathrm{~g}^{-1}\right)$, the material synthesized with $\mathrm{KCl}(\mathrm{ESK}-1.5)$ exhibits a notable improvement of its properties (i.e., a BET surface area of $2590 \mathrm{~m}^{2} \mathrm{~g}^{-1}$ and a volume of $1.58 \mathrm{~cm}^{3} \mathrm{~g}^{-1}$ ) (see Table 1). These results agree with our hypothesis that proposes an enhancement of the reactivity due to the confinement effect of the melted $\mathrm{KCl}$ phase which, obviously, will provoke an increment of the textural development of the carbon materials. Indeed, the porous carbons obtained in the presence of $\mathrm{KCl}$ have high BET surface areas of up to $2650 \mathrm{~m}^{2} \mathrm{~g}^{-1}$ and pore volumes of up to $2.26 \mathrm{~cm}^{3} \mathrm{~g}^{-1}$ (see Table 1 and Table S1). The porosity of these materials is essentially made up of narrow micropores in the case of the carbons produced 
by using $\mathrm{Na}_{2} \mathrm{~S}_{2} \mathrm{O}_{3} /$ precursor weight ratios of $\leq 1$. However, for higher amounts of $\mathrm{Na}_{2} \mathrm{~S}_{2} \mathrm{O}_{3}$ (weight ratio $>1$ ), there is a notable increase in the proportion of large micropores (1-2 $\mathrm{nm})$ and also of small mesopores $(\sim 2-5 \mathrm{~nm})$, as can be deduced from the pore size distributions in Figures $2 \mathrm{~b}$ and $2 \mathrm{~d}$, and also in Figure S2b in the case of gelatin. These results show that the pore structure of these carbons can be easily tuned by simply modifying the amount of $\mathrm{Na}_{2} \mathrm{~S}_{2} \mathrm{O}_{3}$. Significantly, this synthesis strategy produces high carbon yields in the $15-20 \%$ range (Table 1), which is of great importance for the production of these materials on a large scale. For example, in the case of the ESK-1 sample produced from sawdust $\left(S_{B E T}=2350 \mathrm{~m}^{2} \mathrm{~g}^{-1}, V_{\mathrm{p}}=1.13 \mathrm{~cm}^{3} \mathrm{~g}^{-1}\right)$, the carbon yield is $20 \%$ (i.e., $20 \mathrm{~g}$ of porous carbon obtained from $100 \mathrm{~g}$ of raw sawdust). This value is notably superior to the carbon yields obtained for the porous carbons produced with $\mathrm{KOH}(30-40 \%$ smaller $)$ and other chemical activating agents, and noteworthy similar to the carbon yield estimated for the simple pyrolysis of the sawdust. We hypothesize that the confinement effect produced by the presence of inert $\mathrm{KCl}$ particles is responsible for the high carbon yields. We believe that, because the reactions occur in a confined space, the release of volatile compounds is restricted, causing a fraction of the initially emitted gaseous substances to be re-deposited as carbon. Another important advantage of this synthesis procedure is that only moderate amounts of activating agent are required (weight ratio: $\mathrm{Na}_{2} \mathrm{~S}_{2} \mathrm{O}_{3} /$ precursor $\leq 1.5$ ) to achieve a good textural development, in contrast with the large quantities needed in the case of $\mathrm{KOH}$ (usual weight ratio $\sim 4$ ).

The porous carbons obtained by $\mathrm{Na}_{2} \mathrm{~S}_{2} \mathrm{O}_{3}$ activation have a disordered structure, as can be deduced from the X-ray diffraction patterns in Figure 3a. 
This result is corroborated by the Raman spectra obtained for two representative carbon samples, that show two broad bands at $\sim 1350 \mathrm{~cm}^{-1}$ (D band) and $\sim 1600 \mathrm{~cm}^{-1}$ (G band) typical of carbon materials with a disordered structure (see Figure S3) [22]. Despite their lack of graphitic ordering, the carbon samples possess a good electronic conductivity, in the $2.5-4.5 \mathrm{~S} \mathrm{~cm}^{-1}$ range (see Table 1). The packing density of the carbon materials, also shown in Table 1 and which is in the $0.26-0.90 \mathrm{~g} \mathrm{~cm}^{-3}$ range, depend heavily on the development of porosity.

Energy dispersive X-ray spectroscopy (EDX) examination of the carbon samples collected after being washed with water reveal that they are composed exclusively of carbon, sulfur and a small amount of oxygen $(<5 \mathrm{wt} . \%$, according to the elemental chemical analysis) (see Figure 3b). Furthermore, this analysis shows that these materials do not contain any impurity, which proves the efficiency of this benign purification methodology. The sulfur present in these carbon materials has been incorporated into the carbon framework as a consequence of the reactions that occur during the activation process. The EDX mapping in Figure $3 \mathrm{c}$ confirms also that the sulfur is uniformly distributed throughout the carbon particles. The elemental chemical analysis of these samples shows that the porous carbons derived from tannic acid have a notable sulfur content of around $6 \mathrm{wt} . \%$, whereas those synthesized from sawdust or gelatin show moderate percentages of around 2-3 wt.\% (see Table 1 and Table S1). The gelatin-based carbons also contain a certain amount of nitrogen (2-3 wt.\%), derived from the proteins present in raw gelatine. Details of the $\mathrm{N}$-groups present in these carbons is given elsewhere [15]. Information about the chemical nature of the sulfur functional groups was obtained by X-ray 
photoelectron spectroscopy (XPS) analysis. Indeed, the high-resolution S $2 p$ spectrum corresponding to the TAK-1.5 sample (Figure 3d) shows the presence of thiophenic-sulfur motifs (doublet with $2 \mathrm{p}_{3 / 2}=164.2 \mathrm{eV}$ ) and oxidized sulfur (doublet with $2 \mathrm{p}_{3 / 2}=168.3 \mathrm{eV}$ ).

\subsection{Electrochemical performance of the porous carbons produced by means of activation with $\mathrm{Na}_{2} \mathrm{~S}_{2} \mathrm{O}_{3}$}

\subsubsection{Electrochemical performance in aqueous electrolyte}

The most microporous materials, i.e. TAK-1, ESK-1 and GEK-0.7, and a micromesoporous material, GEK-1.3, were analyzed in supercapacitors assembled with an aqueous electrolyte consisting of $1 \mathrm{M} \mathrm{H}_{2} \mathrm{SO}_{4}$, using commercial mass loadings ( $\left.10 \mathrm{mg} \mathrm{cm}^{-2}\right)$. Figure 4 compares the GCD at low and high current densities for the different materials, showing in all the cases symmetric voltage profiles (coulombic efficiency $>98 \%$ ). It can be seen that, at low current densities, the microporous materials show larger capacitance (i.e., the discharge time is longer) than the micro-mesoporous material (see Figure 4a). In fact, the specific capacitance value follows the trend of micropore volume and not that of surface area. Thereby, GEK-0.7 and GEK-1.3 possess the same surface area value (see Table S1), but very different specific capacitances of 202 and $148 \mathrm{~F} \mathrm{~g}^{-1}$ respectively, which implies values of surface area-normalized

capacitance of 9.5 and $6.6 \mu \mathrm{F} \mathrm{cm}^{-2}$ respectively. At a high rate of $20 \mathrm{~A} \mathrm{~g}^{-1}$, all the materials show similar IR drops -below $100 \mathrm{mV}$ - and therefore similar ESR (equivalent series resistance), but different EDR (equivalent distributed resistance), with TAK-1 having the highest EDR and GEK-1.3 the lowest (see Figure 4b). This is confirmed by EIS studies. Thus, as shown by the Nyquist plots in Figure 4c, all the materials have the same point of intersection on the $\mathrm{x}$ - 
axis at the highest frequency (ESR), whereas the length of the Warburg region differs substantially. In agreement with the GCD curves, the material that has the longest Warburg region -and therefore the highest EDR- is TAK-1, whereas GEK-1.3 has the shortest Warburg region. In light of the PSDs of the different materials (Figures 2b, 2d and S1b), the dissimilarities observed in the impedance to the diffusion of ions through the porous structure cannot be attributed exclusively to differences in the size of the pores. Therefore, surface chemistry must also play a role. Thus, TAK-1 exhibits the highest EDR, although it has a higher proportion of pores $>2 \mathrm{~nm}$ than ESK-1 and GEK-0.7. This high EDR can be attributed to its more hydrophobic nature owing to its higher sulfur content (6 wt.\%) [23]. Also worth noting is that all the developed materials show a smaller impedance to ion diffusion than the commercial AC YP-17D (see Figure 4c). These differences in cell resistance finally translate into different rate capabilities, as shown by Figure $4 d$. Thus, TAK-1 shows a capacitance retention of ca. $50 \%$ at $40 \mathrm{~A} \mathrm{~g}^{-1}$ vs. $67-70 \%$ for ESK-1 and GEK0.7 , and $83 \%$ for GEK-1.3. The improved rate capability of micro-mesoporous materials is proved by a capacitance retention of ca. $70 \%$ for GEK-1.3 at an ultra-high discharge current density of $110 \mathrm{~A} \mathrm{~g}^{-1}$, so that this material still has a capacitance of ca. $100 \mathrm{~F} \mathrm{~g}^{-1}$ at such an ultra-high rate (see Figure S4 for the voltage profile at $\left.110 \mathrm{~A} \mathrm{~g}^{-1}\right)$. Such high rate capabilities are rarely reported when using commercial mass loadings [14, 24, 25], but normally for electrode loadings $<2 \mathrm{mg} \mathrm{cm}^{-2}$.

The stability of the supercapacitors was analyzed by GCD over 8000 cycles at $5 \mathrm{~A} \mathrm{~g}^{-1}$ followed by $24 \mathrm{~h}$ of floating at the maximum cell voltage (i.e., 1 V). As Figure S5 shows, all the supercapacitors exhibit an excellent stability 
under cycling and voltage hold conditions, with a 97-100\% capacitance retention in both cases.

\subsubsection{Electrochemical performance in non-aqueous electrolytes}

The electrochemical performance of the materials was also analyzed in organic (1 $\left.\mathrm{M} \mathrm{TEABF}_{4} / \mathrm{AN}\right)$ and ionic liquid (EMImTFSI) electrolytes, which allow cell voltages of up to 2.7 and $3 \mathrm{~V}$ respectively, enhancing the amount of energy stored in the device. In this case, materials with a larger proportion of mesopores were analyzed. Figures $5 \mathrm{a}-5 \mathrm{~b}$ show the $\mathrm{CVs}$ at different scan rates in organic electrolyte for the supercapacitors assembled with TAK-1.5 and ESK1.5 respectively, whereas Figures $5 c-5 d$ show their $C V s$ in ionic liquid electrolyte. Both materials show typical EDLC behaviour in organic electrolyte, which is characterized by rectangular-shaped CVs, while they display some redox behaviour in EMImTFSI, with broad humps in the cell voltage range of 1-2 $V$ at low scan rates. These humps are more pronounced in the case of the materials derived from tannic acid, which contains higher amounts of sulfur (vide supra). In the case of the N,S-doped materials derived from gelatine (GEK-0.7 and GEK-1.3), there are no discernible humps in either of the electrolytes, as shown by the CVs in Figure S6, suggesting either the absence of a redox contribution or the superimposition of the redox contribution by the Sand $\mathrm{N}$-groups. In order to elucidate the origin of the humps, a two-electrode cell

equipped with a Ag pseudo-reference electrode was used. The corresponding $\mathrm{CVs}$ at $5 \mathrm{mV} \mathrm{s}^{-1}$ for the positive and negative electrodes are presented in Figure S7. As can be seen, the chemical nature of the material strongly influences the potential of zero voltage. Besides, in the case of the tannic acid-based material (TAK-1.5), which has the largest sulfur content $(\mathrm{S}=6.2 \mathrm{wt} \%)$, clearly defined 
redox peaks are observed in both electrodes (Figure S7a), which leads to electrodes with similar capacitance values and also a similar working potential window $\left(\mathrm{V}_{-} / \mathrm{V}_{+}=1.08\right)$, and finally leads to the observation of more pronounced humps in the two-electrode cell. In the case of the sawdust-derived material (ESK-1.5, S $=2.4 \mathrm{wt} \%$ ), only the positive electrode exhibits intense redox peaks (at around $1 \mathrm{~V} v s$. Ag in both the anodic and the cathodic scans, as in the case of TAK-1.5) (Figure S7b). This leads to a substantial dissimilarity in capacitance between the positive and the negative electrode, so that the working potential window of the positive electrode is much smaller than that of the negative one $\left(\mathrm{V}-\mathrm{V}_{+}=1.43\right)$. Taking into account that this material possesses the more positive potential of zero voltage, the larger capacitance of the positive electrode is advantageous as it impedes it from working at high potentials where it may oxidize. Finally, the gelatine-derived material $(\mathrm{GEK}-0.7, \mathrm{~S}=2.73$ wt $\%$ and $\mathrm{N}=3.30$ wt\%) shows no distinctive redox peaks in either of the electrodes (Figure S7c), which agrees with the square-shaped CVs obtained in the two-electrode cell. As a result, the electrodes show a balanced performance, with similar values of capacitance and working potential windows $\left(V_{-} / V_{+}=1.08\right)$. The synchronous two- and three- electrode CVs also reveal the stability of the different systems for a cell voltage of $3 \mathrm{~V}$, with no sharp cathodic/anodic currents at the negative/positive electrodes respectively for the extreme potentials. However, when long-term cycling is performed, different capacitance retentions are observed (Figure S8a). This is ascribable to the reduction of the redox activity with galvanostatic charge/discharge cycling, as evidenced by a comparison of the CVs before and after long-term cycling (Figure S8b-d). In this way, an inverse proportional relationship is found 
between the long-term capacitance retention and the amount of sulfur. Nevertheless, all the materials are able to retain more than $90 \%$ of the capacitance after $8000 \mathrm{GCD}$ cycles at $3 \mathrm{~A} \mathrm{~g}^{-1}$. Similarly, in the organic electrolyte, the capacitance retention after 8000 cycles at $5 \mathrm{~A} \mathrm{~g}^{-1}$ is in the range of $95-96 \%$ and $>97 \%$ after $24-48 \mathrm{~h}$ at $2.7 \mathrm{~V}$ (see Figure S9). These results prove the good stability of the materials in the different types of electrolytes.

The CVs in Figures 5 and S6 further reveal the good rate performance in the organic and ionic liquid electrolytes at commercial mass loadings. Thus, the materials are able to work up to $200-300 \mathrm{mV} \mathrm{s}^{-1}$ in the organic electrolyte and up to $50 \mathrm{mV} \mathrm{s}^{-1}$ in the ionic liquid. Further testing of the supercapacitors by GCD cycling confirms the good capacitance retention with the increase in discharge current. As can be seen in Figure 6a, in organic electrolyte, all the materials show a capacitance retention $>70 \%$ at $30 \mathrm{~A} \mathrm{~g}^{-1}$ and additionally the materials with the largest proportion of mesopores (i.e., TAK-1.5, TAK-1.5L and GEK-1.3) are able to work up to $40 \mathrm{~A} \mathrm{~g}^{-1}$ with a capacitance retention of $60-75 \%$. As in the case of the aqueous electrolyte, GEK-1.3 excels in rate-handling ability, although it shows a slightly lower capacitance at low rates. In the neat ionic liquid (Figure $6 \mathrm{~b}$ ), the rate capability of all the materials is lower, as might be expected from its higher viscosity and lower ionic conductivity (see Figure S10 for a comparison of the Nyquist plots and frequency response in the different electrolytes). Nevertheless, the materials retain more than $60 \%$ of the capacitance for a 25-fold increase in current, i.e. from 0.2 to $5 \mathrm{~A} \mathrm{~g}^{-1}$. The capacitance values in both electrolytes $\left(\sim 125-140\right.$ and $150-160 \mathrm{~F} \mathrm{~g}^{-1}$ at low rate for the organic and ionic liquid electrolytes, respectively) are similar to the stateof-the-art values for carbon materials and ACs (including $\mathrm{KOH}-\mathrm{ACs}$ ) [14, 26-35], 
and are superior to those of commercial ACs targeted at supercapacitors $(<110$ $\left.\mathrm{F} \mathrm{g}^{-1}\right)[14,36]$. These capacitance values in the ionic liquid electrolyte suggest that the impact of S-groups on capacitance through pseudocapacitance contribution is not significant in the two-electrode system. Thus, the materials showing the largest surface area-normalized capacitance (TAK-1 and GEK-0.7, 6.3 and $7 \mu \mathrm{F} \mathrm{cm}^{-2}$ respectively) are the ones with the highest amount of micropores and not the one with the highest amount of sulfur. Similarly, TAK-1 has a larger surface area-normalized capacitance than TAK-1.5 $\left(5.9 \mu \mathrm{F} \mathrm{cm}{ }^{-2}\right)$ despite having the same amount of sulfur (see Table 1).

Figures $6 c$ and $6 d$ gather the energy and power characteristics of the devices in a Ragone-like plot, evaluated both in gravimetric and volumetric terms, for the different electrolytes. The organic electrolyte-based systems are able to store 32-36 $\mathrm{Wh} \mathrm{kg}^{-1}\left(8-13 \mathrm{Wh} \mathrm{L}^{-1}\right)$ at low power $\left(140 \mathrm{~W} \mathrm{~kg}^{-1} / 30-40 \mathrm{~W} \mathrm{~L}^{-1}\right)$ and even as much as 15-20 Wh kg-1 (3-6 $\left.\mathrm{Wh} \mathrm{L}^{-1}\right)$ at high power densities of 18$26 \mathrm{~kW} \mathrm{~kg}^{-1}\left(6-7 \mathrm{~kW} \mathrm{~L}^{-1}\right)$. By using the ionic liquid electrolyte, the amount of energy stored at low power can be increased to $47-51 \mathrm{Wh} \mathrm{kg}^{-1}\left(11-18 \mathrm{Wh} \mathrm{L}^{-1}\right)$, but the maximum power is limited to $4-5.5 \mathrm{~kW} \mathrm{~kg}^{-1}\left(1.2-1.7 \mathrm{~kW} \mathrm{~L}^{-1}\right)$ when commercial mass loadings are used. It would be necessary to improve the packing density of the materials (for example by ball-milling) for the practical application of these materials. Assuming that commercial-level mass loadings are used, the amount of energy stored in a package device (typically $30 \%$ of active material) can be extrapolated. From this extrapolation it can be inferred that $\geq 10 \mathrm{Wh} \mathrm{kg}^{-1}$ is stored at low power independently of the electrolyte considered and still 4.5-6 $\mathrm{Wh} \mathrm{kg}^{-1}$ at 5-8 $\mathrm{W} \mathrm{kg}^{-1}$ in organic electrolyte.

\section{Conclusions}


In summary, we present a sustainable and green synthesis approach for obtaining highly porous carbons based on the chemical activation of various biomass products (wood sawdust, tannic acid or gelatin) with sodium thiosulfate in the presence of an inert template $(\mathrm{KCl})$ that provides a confinement reaction medium. This synthesis strategy gives rise to carbons with several significant properties: i) a good textural development (i.e. BET surface areas of up to 2650 $\mathrm{m}^{2} \mathrm{~g}^{-1}$ and pore volumes of up to $2.3 \mathrm{~cm}^{3} \mathrm{~g}^{-1}$ ), ii) a tunable porosity, iii) a high electronic conductivity and iv) a certain sulfur doping. In addition, these carbon materials are obtained in high yields, which confirms the potential for scaling up to industrial level. The porous carbons produced in this study offer a good performance as electrodes in supercapacitors with a variety of electrolytes. Thus, electrode specific capacitances of up to $200 \mathrm{~F} \mathrm{~g}^{-1}$ are obtained at low rates in aqueous electrolyte, and up to 140 and $160 \mathrm{~F} \mathrm{~g}^{-1}$ for an organic and an ionic liquid electrolyte respectively. Enhanced rate capability can also be obtained under high power conditions with the appropriate tuning of the pore size distribution, up to $80 \%$ at $40 \mathrm{~A} \mathrm{~g}^{-1}$ in aqueous electrolyte, $75 \%$ in organic electrolyte, and more than $60 \%$ at $\% 5 \mathrm{~A} \mathrm{~g}^{-1}$ in neat ionic liquid using commercial-level electrode mass loadings.

\section{Acknowledgments}

This research work was supported by the Spanish MINECO-FEDER (CTQ2015$63552-R)$.

\section{References}

[1] B. Lars, O. Martin, K. Stefan. Carbon Materials for Lithium Sulfur BatteriesTen Critical Questions. Chemistry - A European Journal 22 (2016) 7324-7351. 
[2] D.-W. Wang, F. Li, M. Liu, G.Q. Lu, H.-M. Cheng. 3D Aperiodic Hierarchical Porous Graphitic Carbon Material for High-Rate Electrochemical Capacitive Energy Storage. Angew Chem Int Ed 47 (2008) 373-376.

[3] H. Nishihara, T. Kyotani. Templated nanocarbons for energy storage. Adv Mater 24 (2012) 4473-4498.

[4] M. Inagaki, M. Toyoda, Y. Soneda, S. Tsujimura, T. Morishita. Templated mesoporous carbons: Synthesis and applications. Carbon 107 (2016) 448-473.

[5] S. Schrettl, B. Schulte, H. Frauenrath. Templating for hierarchical structure control in carbon materials. Nanoscale 8 (2016) 18828-18848.

[6] V. Presser, M. Heon, Y. Gogotsi. Carbide-Derived Carbons - From Porous Networks to Nanotubes and Graphene. Adv Funct Mater 21 (2011) 810-833.

[7] J. Wang, S. Kaskel. KOH activation of carbon-based materials for energy storage. J Mater Chem 22 (2012) 23710-23725.

[8] M. Sevilla, R. Mokaya. Energy storage applications of activated carbons: supercapacitors and hydrogen storage. Energy Environ Sci 7 (2014) 1250-1280.

[9] C. Schneidermann, N. Jäckel, S. Oswald, L. Giebeler, V. Presser, L. Borchardt. Solvent-Free Mechanochemical Synthesis of Nitrogen-Doped Nanoporous Carbon for Electrochemical Energy Storage. ChemSusChem 10 (2017) 2416-2424.

[10] Y. Sun, J. Wei, Y.S. Wang, G. Yang, J.P. Zhang. Production of activated carbon by $\mathrm{K} 2 \mathrm{CO} 3$ activation treatment of cornstalk lignin and its performance in removing phenol and subsequent bioregeneration. Environ Technol 31 (2010) 53-61.

[11] J. Deng, T. Xiong, F. Xu, M. Li, C. Han, Y. Gong, et al. Inspired by bread leavening: one-pot synthesis of hierarchically porous carbon for supercapacitors. Green Chem 17 (2015) 4053-4060.

[12] M. Sevilla, A.B. Fuertes. A Green Approach to High-Performance Supercapacitor Electrodes: The Chemical Activation of Hydrochar with Potassium Bicarbonate. ChemSusChem 9 (2016) 1880-1888.

[13] M. Sevilla, G.A. Ferrero, A.B. Fuertes. One-Pot Synthesis of Biomass-Based Hierarchical Porous Carbons with a Large Porosity Development. Chem Mater 29 (2017) 6900-6907.

[14] M. Sevilla, G.A. Ferrero, A.B. Fuertes. Beyond KOH activation for the synthesis of superactivated carbons from hydrochar. Carbon 114 (2017) 50-58.

[15] A.B. Fuertes, G.A. Ferrero, N. Diez, M. Sevilla. A Green Route to High-Surface Area Carbons by Chemical Activation of Biomass-Based Products with Sodium Thiosulfate. ACS Sustain Chem Eng 6 (2018) 16323-16331.

[16] W.E. Kleinjan, A.d. Keizer, A.J.H. Janssen. Kinetics of the chemical oxidation of polysulfide anions in aqueous solution. Water Research 39 (2005) 4093-4100.

[17] R. Steudel, G. Holdt, R. Nagorka. On the Autoxidation of Aqueous Sodium Polysulfide [1]. Zeitschrift für Naturforschung B 1986, p. 1519.

[18] ISO 9277:2010. Determination of the specific surface area of solids by gas adsorption - BET method. Second Edition of ISO 9277, ISO. Geneva; 2012.

[19] M.D. Stoller, R.S. Ruoff. Best practice methods for determining an electrode material's performance for ultracapacitors. Energy Environ Sci 3 (2010) 1294-1301.

[20] A.B. Fuertes, G.A. Ferrero, M. Sevilla. Commentary: Methods of calculating the volumetric performance of a supercapacitor. Energy Storage Mater 4 (2016) 154-155.

[21] H.N. Tran, D. Barham. The System Na2SO4-Na2S. International Conference on the Recovery of Pulping Chemicals. Vancouver (Canada); p. 67-70.

[22] A. Cuesta, P. Dhamelincourt, J. Laureyns, A. Martínez-Alonso, J.M.D. Tascón. Raman microprobe studies on carbon materials. Carbon 32 (1994) 1523-1532. 
[23] S. Mykola, L. Krisztina, B.T. J. Sulfur-Doped Carbon Aerogel as a Metal-Free Oxygen Reduction Catalyst. ChemCatChem 7 (2015) 2924-2931.

[24] J. Pokrzywinski, J.K. Keum, R.E. Ruther, E.C. Self, M. Chi, H. Meyer, III, et al. Unrivaled combination of surface area and pore volume in micelle-templated carbon for supercapacitor energy storage. J Mater Chem A 5 (2017) 13511-13525.

[25] N. Mao, H. Wang, Y. Sui, Y. Cui, J. Pokrzywinski, J. Shi, et al. Extremely highrate aqueous supercapacitor fabricated using doped carbon nanoflakes with large surface area and mesopores at near-commercial mass loading. Nano Res 10 (2017) 1767-1783.

[26] M. Sevilla, A.B. Fuertes. Direct Synthesis of Highly Porous Interconnected Carbon Nanosheets and Their Application as High-Performance Supercapacitors. ACS Nano 8 (2014) 5069-5078.

[27] Y. Cui, H. Wang, N. Mao, W. Yu, J. Shi, M. Huang, et al. Tuning the morphology and structure of nanocarbons with activating agents for ultrafast ionic liquid-based supercapacitors. J Power Sources 361 (2017) 182-194.

[28] Y. Zhu, S. Murali, M.D. Stoller, K.J. Ganesh, W. Cai, P.J. Ferreira, et al. Carbon-Based Supercapacitors Produced by Activation of Graphene. Science 332 (2011) 1537-1541.

[29] Y. Cui, H. Wang, X. Xu, Y. Lv, J. Shi, W. Liu, et al. Nitrogen-doped porous carbons derived from a natural polysaccharide for multiple energy storage devices. Sust Energy Fuels 2 (2018) 381-391.

[30] R. Yan, M. Antonietti, M. Oschatz. Toward the Experimental Understanding of the Energy Storage Mechanism and Ion Dynamics in Ionic Liquid Based Supercapacitors. Adv Energy Mater 8 (2018) 1800026.

[31] M. Oschatz, S. Boukhalfa, W. Nickel, J.P. Hofmann, C. Fischer, G. Yushin, et al. Carbide-derived carbon aerogels with tunable pore structure as versatile electrode material in high power supercapacitors. Carbon 113 (2017) 283-291.

[32] R. Shao, J. Niu, J. Liang, M. Liu, Z. Zhang, M. Dou, et al. Mesopore- and Macropore-Dominant Nitrogen-Doped Hierarchically Porous Carbons for High-Energy and Ultrafast Supercapacitors in Non-Aqueous Electrolytes. ACS App Mater Interfases 9 (2017) 42797-42805.

[33] N. Guo, M. Li, X. Sun, F. Wang, R. Yang. Tremella derived ultrahigh specific surface area activated carbon for high performance supercapacitor. Materials Chemistry and Physics 201 (2017) 399-407.

[34] M. Jia, P.-p. Chang, C.-y. Wang, M.-m. Chen. Humic acid-derived hierarchical porous carbon preparation using vacuum freeze-drying for electric double layer capacitors. J Chin Chem Soc 65 (2018) 835-840.

[35] Q.-L. Zhu, P. Pachfule, P. Strubel, Z. Li, R. Zou, Z. Liu, et al. Fabrication of nitrogen and sulfur co-doped hollow cellular carbon nanocapsules as efficient electrode materials for energy storage. Energy Storage Mater 13 (2018) 72-79.

[36] L. Wei, M. Sevilla, A.B. Fuertes, R. Mokaya, G. Yushin. Hydrothermal Carbonization of Abundant Renewable Natural Organic Chemicals for HighPerformance Supercapacitor Electrodes. Adv Energy Mater 1 (2011) 356-361. 
Table 1. Physico-chemical properties of porous carbons produced from eucalyptus sawdust and tannic acid using $\mathrm{Na}_{2} \mathrm{~S}_{2} \mathrm{O}_{3}$ as activating agent.

\begin{tabular}{lllllllll}
\hline $\begin{array}{l}\text { Carbon } \\
\text { Precursor }\end{array}$ & $\begin{array}{l}\text { Sample } \\
\text { code }\end{array}$ & $\begin{array}{l}\text { Yield } \\
(\%)\end{array}$ & $\begin{array}{l}\mathrm{S}_{\mathrm{BET}} \\
\left(\mathrm{m}^{2} \mathrm{~g}^{-1}\right)\end{array}$ & $\begin{array}{l}\mathrm{V}_{\mathrm{p}} \\
\left(\mathrm{cm}^{3} \mathrm{~g}^{-1}\right)\end{array}$ & $\begin{array}{l}\mathrm{V}_{\text {micro }} \\
\left(\mathrm{cm}^{3} \mathrm{~g}^{-1}\right)\end{array}$ & $\begin{array}{l}\text { Sulfur } \\
(\text { wt.\%) }\end{array}$ & $\begin{array}{l}\text { Electrical } \\
\text { conductivity } \\
\left(\mathrm{S} \mathrm{cm}^{-1}\right)\end{array}$ & $\begin{array}{l}\text { Packing } \\
\text { density } \\
\left(\mathrm{g} \mathrm{cm}^{-3}\right)\end{array}$ \\
\hline Eucaliptus & ES-1.5 & 14 & 1070 & 0.56 & 0.41 & 11.3 & 3.2 & 0.80 \\
& ESK-1 & 20 & 2350 & 1.13 & 0.93 & 2.1 & 2.4 & 0.60 \\
& ESK-1.5 & 14 & 2590 & 1.58 & 0.93 & 2.4 & 2.9 & 0.52 \\
\hline Tannic acid & TA-1.5 & - & 1110 & 0.59 & 0.42 & 8.6 & 2.8 & 0.90 \\
& TAK-1 & 21 & 2630 & 1.39 & 1.0 & 6.0 & 3.8 & 0.46 \\
& TAK-1.5 & 16 & 2650 & 1.95 & 0.82 & 6.2 & 2.5 & - \\
& TAK-1.5L & 17 & 2590 & 2.26 & 0.80 & 5.1 & 4.5 & 0.26 \\
\hline
\end{tabular}




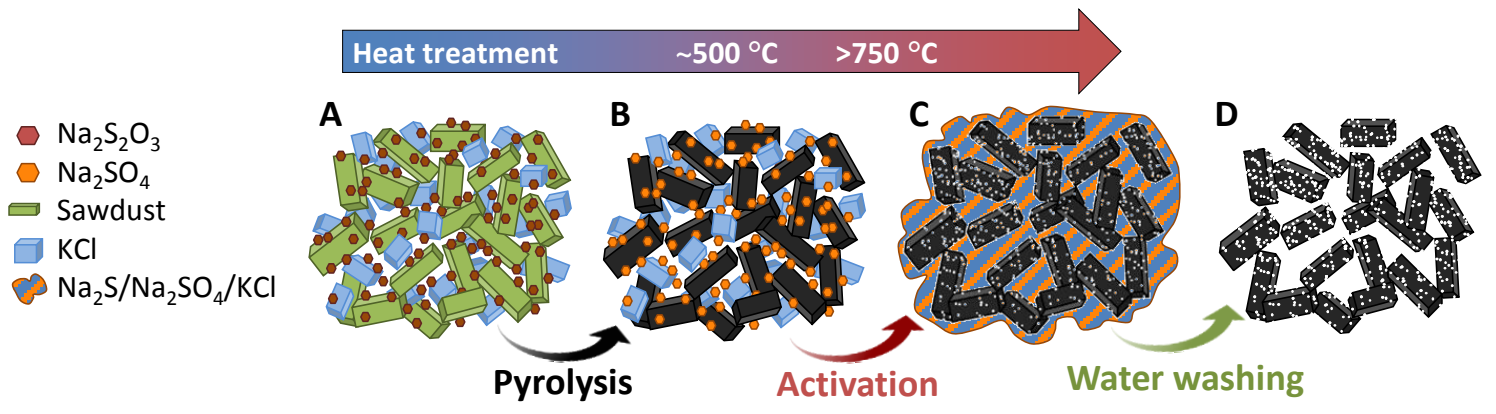

Scheme 1. Illustration of the synthesis procedure. (A) Blend of the raw materials (i.e. sawdust, $\mathrm{KCl}$ and $\mathrm{Na}_{2} \mathrm{~S}_{2} \mathrm{O}_{3}$ ); (B) Mixture of the pyrolyzed sawdust with $\mathrm{KCl}$ and $\mathrm{Na}_{2} \mathrm{SO}_{4}$; (C) Porous carbon-KCl-Na $\mathrm{S}$ monolith; (D) Porous carbon. 

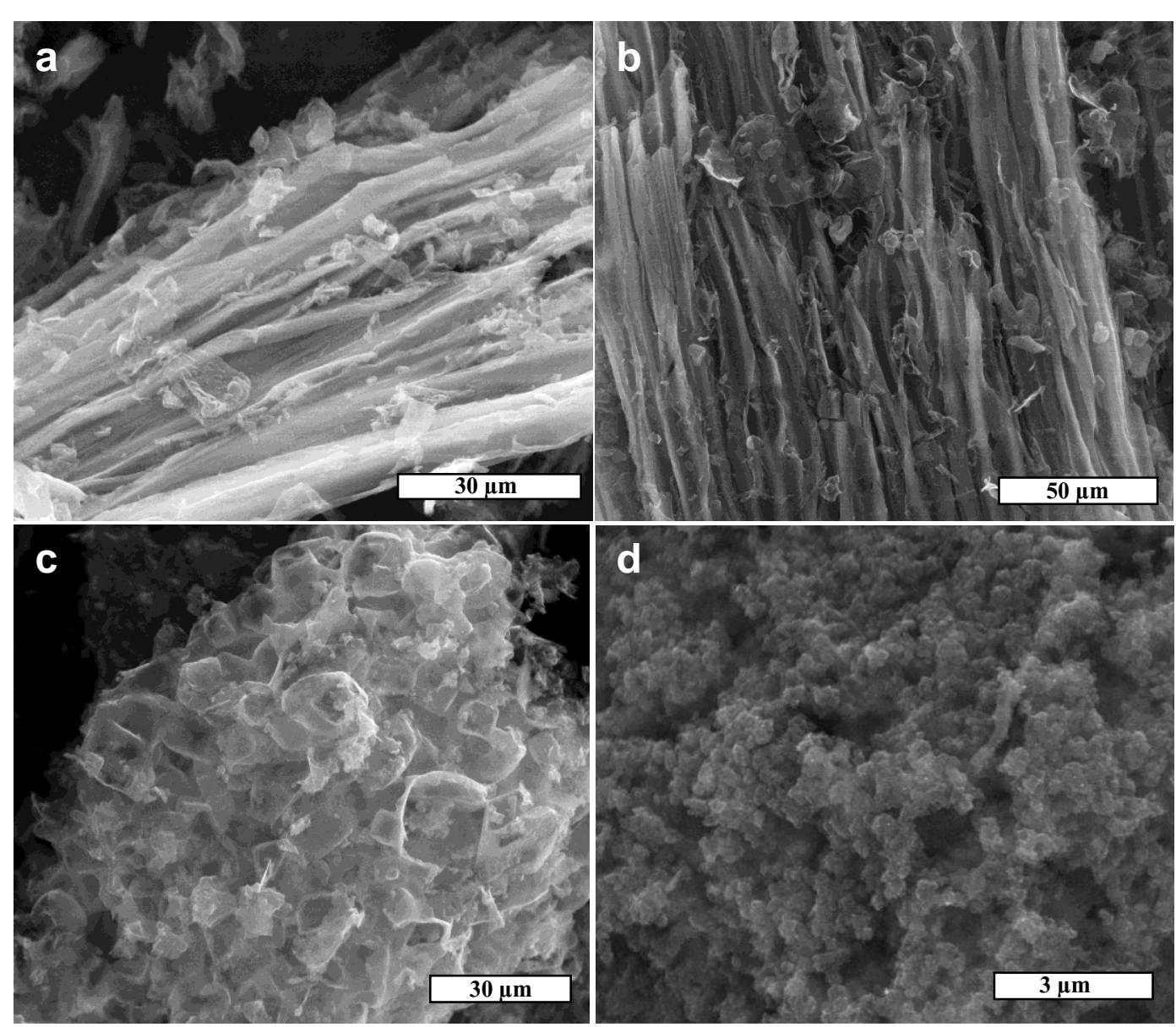

Figure 1. SEM micrographs of the carbon materials produced from sawdust (a: ESK-1.5, b: ESK-1) and tannic acid (c: TAK-1.5L, d: TAK-1.5). 

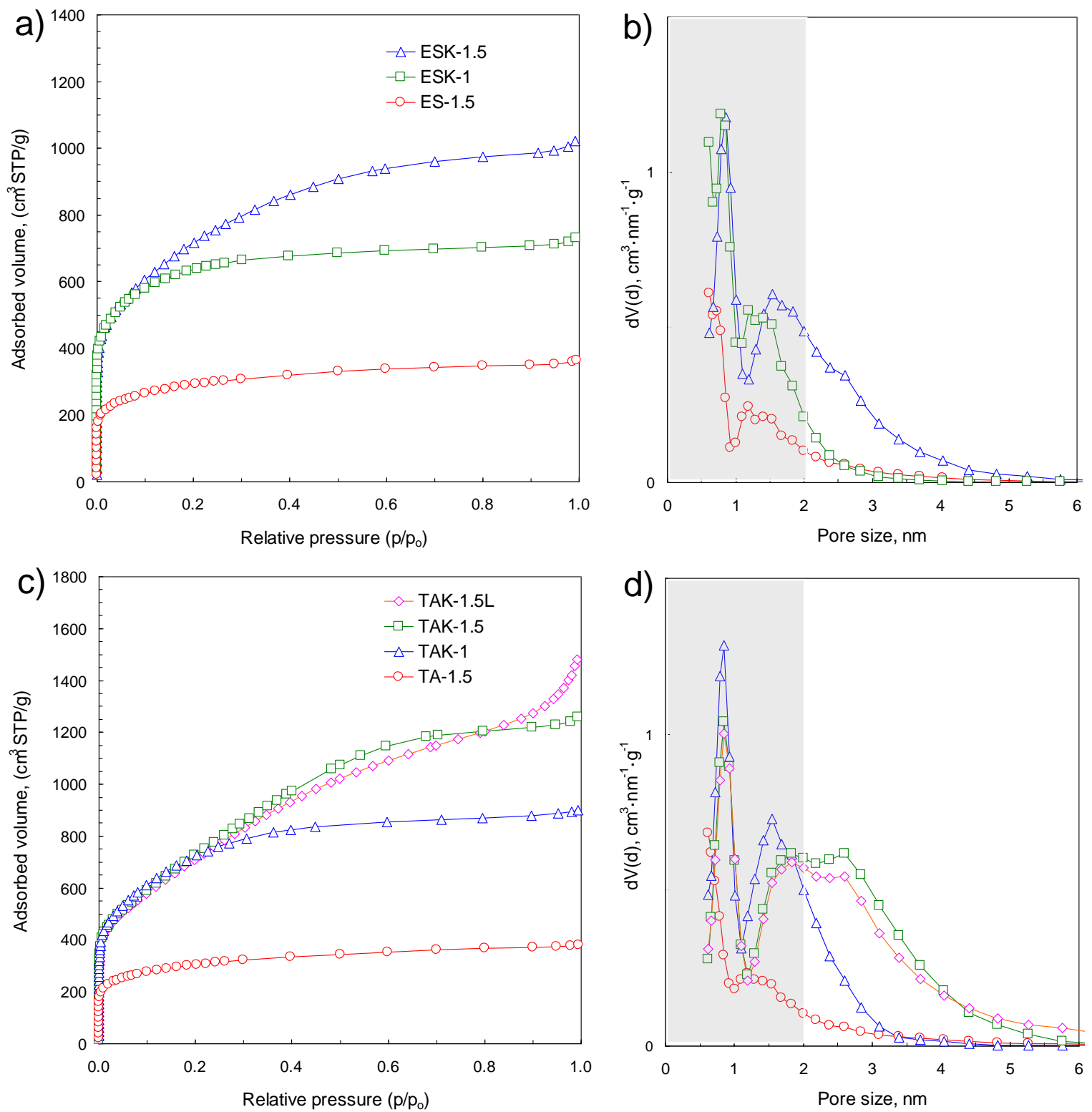

Figure 2. a) Nitrogen adsorption isotherms and b) pore size distributions of the porous carbons obtained from sawdust ( $a, b)$ and tannic acid (c, d) under different operational conditions. The shaded area in (b) and (d) indicates the micropore range. 


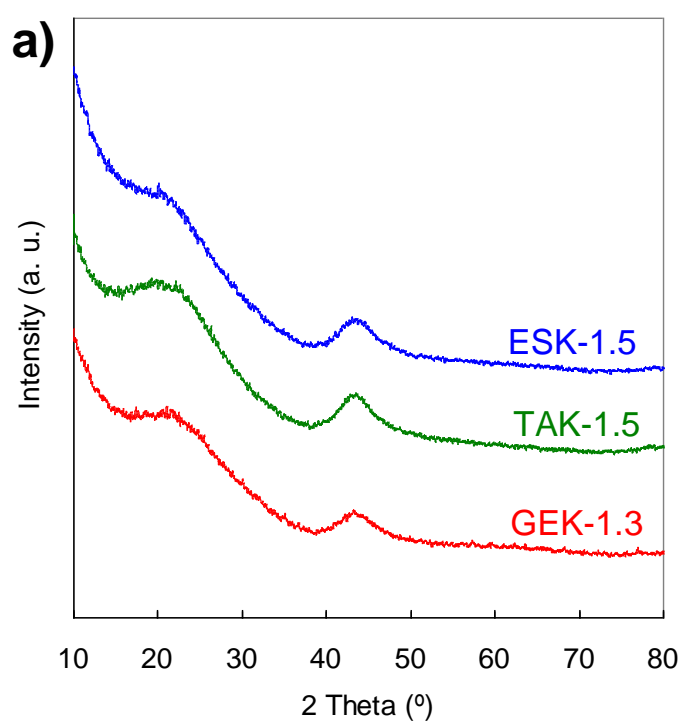

b)

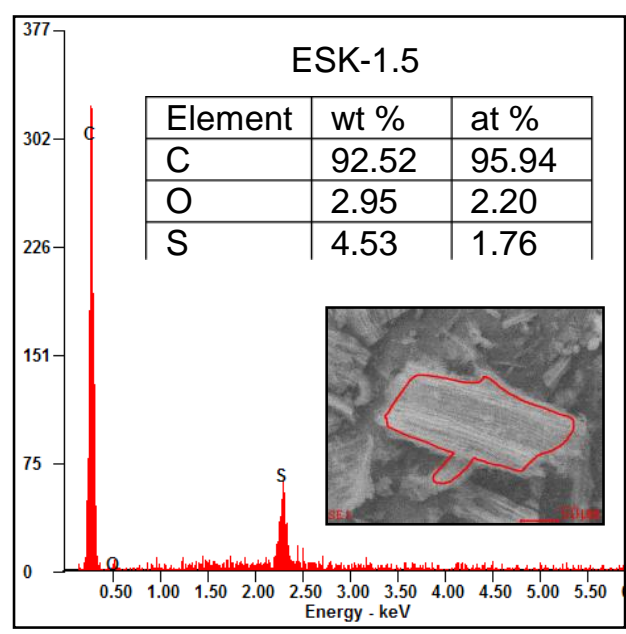

c)
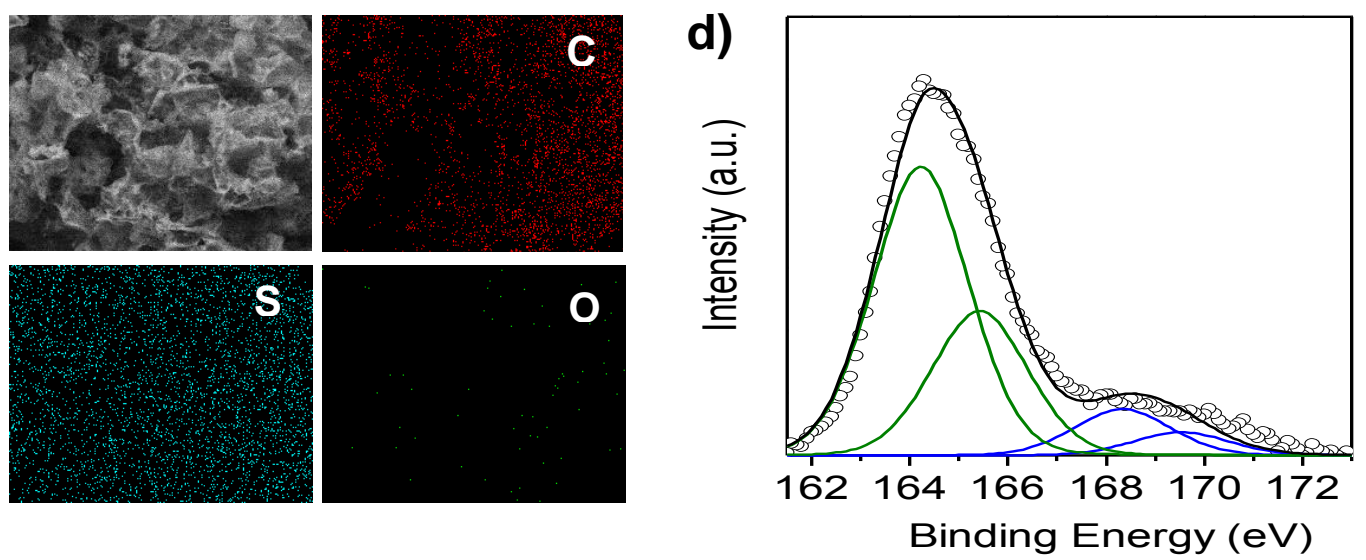

Figure 3. a) XRD patterns, b) EDX analysis, c) EDX mapping of $C, S$, and $O$ (Sample: TAK-1.5) and d) the high-resolution S 2p XPS spectrum of TAK-1.5. 

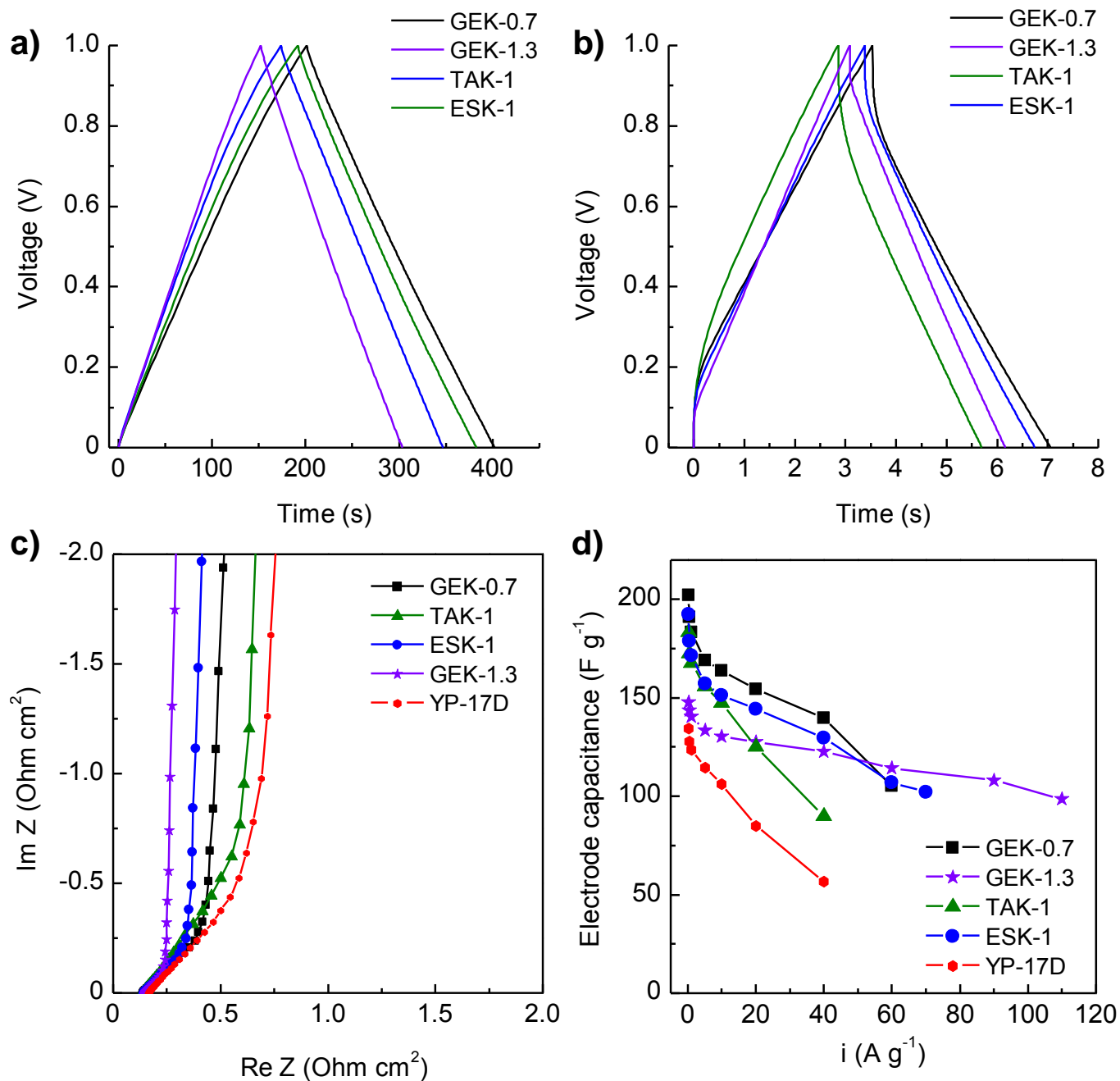

Figure 4. a) GCD voltage profiles at $0.5 \mathrm{~A} \mathrm{~g}^{-1}$, b) GCD voltage profiles at $20 \mathrm{~A}$ $\mathrm{g}^{-1}$, c) Nyquist plots and d) rate capability evaluated by GCD for several microporous carbons (GEK-0.7, TAK-1 and ESK-1), a micro-mesoporous carbon (GEK-1.3), and a commercial AC (YP-17D). Electrolyte: $\mathrm{H}_{2} \mathrm{SO}_{4}$. 

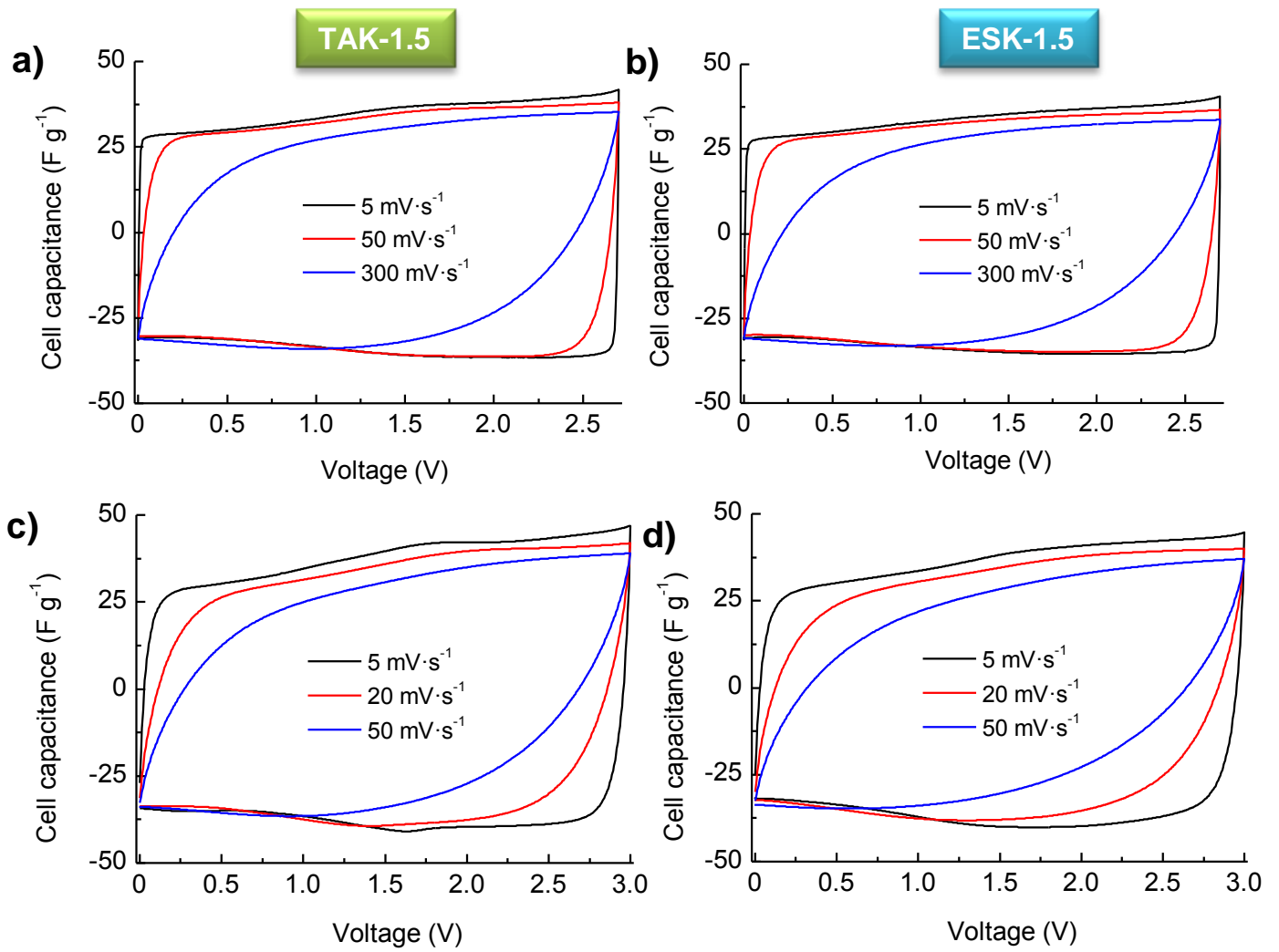

Figure 5. CVs in organic electrolyte for a) TAK-1.5 and b) ESK-1.5, and in ionic liquid electrolyte for c) TAK-1.5 and d) ESK-1.5. 
a)

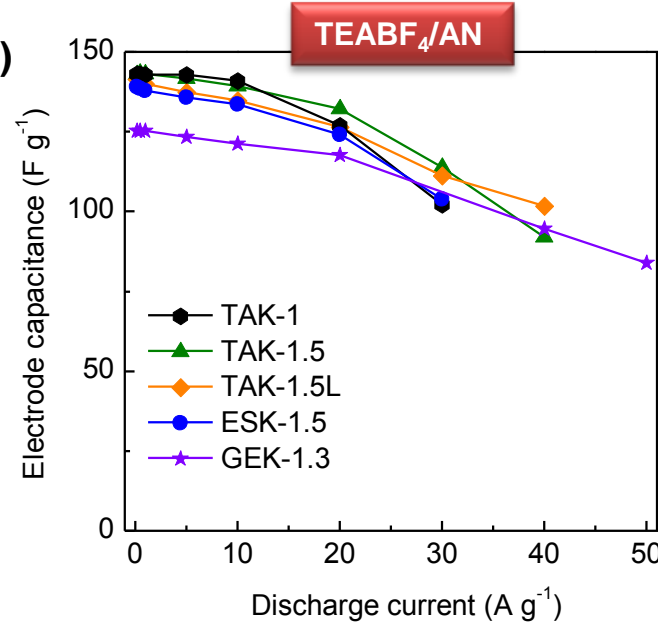

c)

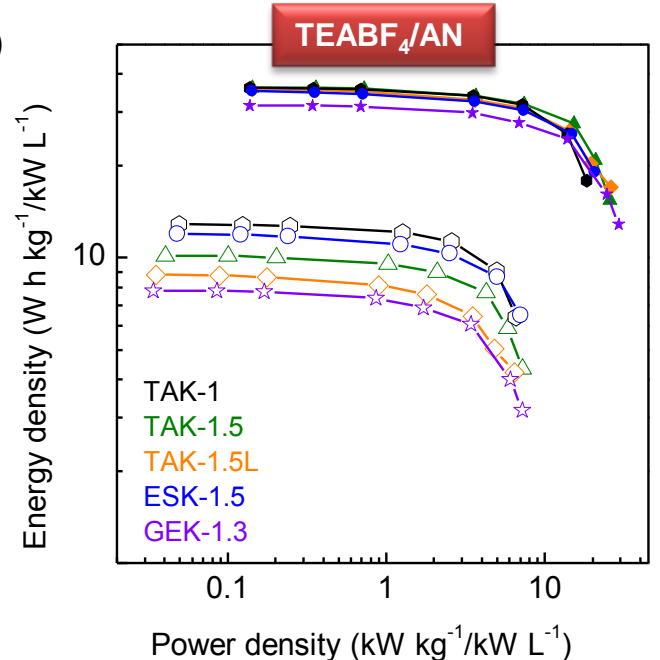

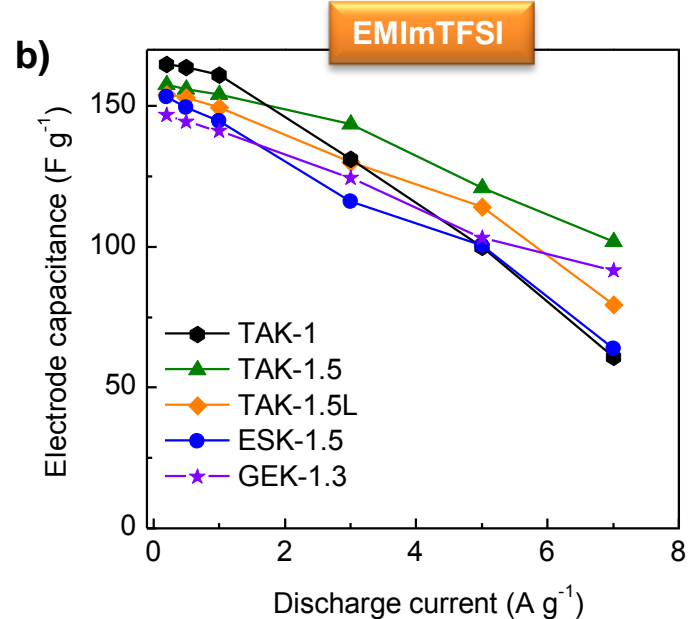

d)

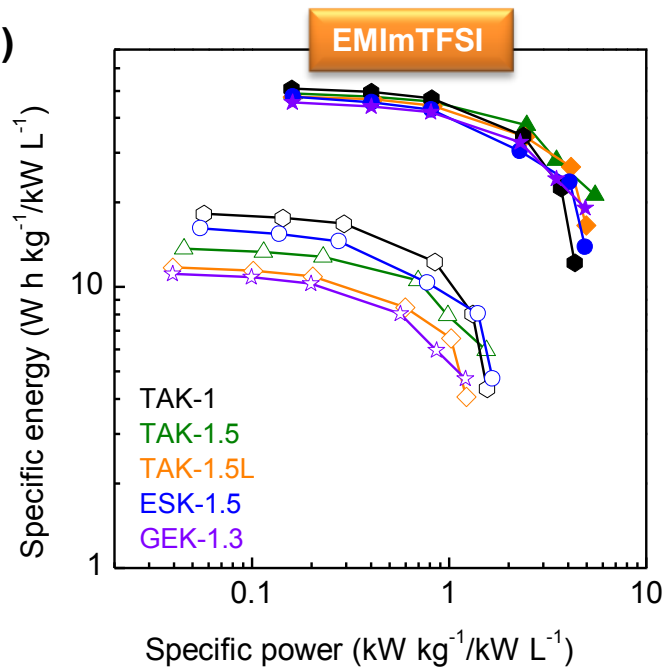

Figure 6. Rate capability as evaluated by GCD in a) organic electrolyte and b) ionic liquid electrolytes, and Ragone-like plots for c) organic electrolyte and d) ionic liquid electrolytes (closed symbols: gravimetric performance, open symbols: volumetric performance). 